\title{
Historicizando o Novo Consumerismo Global Sob uma Perspectiva de Mundos Emergentes
}

Historicizing the New Gobal Consumerism From a Perspective of Emerging Worlds Pontifícia Universidade Católica do Rio de Janeiro, Escola de Negócios, Rio de Janeiro, RJ, Brasil ${ }^{2}$ 


\title{
Resumo
}

O avanço da desigualdade, da injustiça e da discriminação, e a emergência de movimentos anticonsumerismo no contexto do capitalismo neoliberal global, informam a explosão de debates corporações-sociedade no campo de Organizações e Gestão $(\mathrm{O} \& \mathrm{G})$ e a construção do novo consumerismo global (NCG). Esse quadro é marcado pela radicalização da negação da face racialista do capitalismo modernista por historicismos antiamericanismo na Europa e na América Latina, que também desestabilizam e reforçam a rearticulação do historicismo discriminatório em consumerismo pelo NCG. Usando uma perspectiva crítica transmoderna enunciada em país emergente da América Latina, indo além das dicotomizações americanismo versus antiamericanismo e consumerismo versus anticonsumerismo, este artigo re-historiciza o movimento consumerista dos EUA, para mostrar que passados negados pelo anti-antiamericanismo racialista desempoderam academia e sociedade por meio de dinâmicas de apropriação e contenção de alternativas e identidades não discriminatórias, mobilizadas por mundos emergentes. Análise mostra que historicizações transmodernas podem permitir que NCG e o campo de $\mathrm{O} \& \mathrm{G}$ recuperem identidades discriminadas, promovam conhecimento para e com a maioria, ao invés de minorias, e atenuem o avanço do autoritarismo populista mobilizado pela supremacia branca.

Palavras-chave: consumerismo; globalização neoliberal; história; economias emergentes.

\begin{abstract}
The advancement of inequality, injustice and discrimination, and the emergence of anticonsumerist movements within the context of global neoliberal capitalism inform the corporation-society debates in the field of Management \& Organizational Studies (MOS) and the construction of the new global consumerism (NGC). This context is marked by the radicalization of the negation of the racialist side of modernist capitalism in Europe and Latin America, which also destabilize and reinforce the re-articulation of discriminatory anti-anti-Americanism historicism in consumerism by the NGC. Grounded on a critical transmodern perspective enunciated in a Latin American emerging country that goes beyond Americanism versus anti-Americanism and consumerism versus anti-consumerism dichotomies, this article re-historicizes the consumerist movement in the US to show that pasts denied by anti-anti-Americanism disempower academia and society through dynamics of appropriation and containment of non-discriminatory alternatives and identities mobilized by emerging worlds. Analysis shows that this transmodern historicism can help NGC and MOS recover discriminated identities, promote knowledge for and with the majority, not minorities, and attenuate advances of populist authoritarianism mobilized by white supremacy.
\end{abstract}

Key words: consumerism; neoliberal globalization; history; emerging economies.

JEL Classification Codes: F6, N16, J15. 


\section{Introdução}

O avanço da desigualdade, da injustiça e da discriminação no contexto do capitalismo neoliberal global - comandado pelos Estados Unidos (EUA) e liderado por grandes corporações e elites oligárquicas financistas (Bloom, 2016; Piketty, 2014; Santos, 2006) - vem sendo acompanhado por movimentos anticonsumerismo (Sklair, 2011) e antieurocentrismo (Mignolo, 2011) e pela explosão de discursos corporações-sociedade que informam a construção do novo consumerismo global (NCG) (e.g., Ger \& Belk, 1996), focado na gestão responsável de e em mundos emergentes específicos.

Esse quadro é marcado por historicismos antiamericanismos mobilizados por autores eurobritânicos (Gienow-Hecht, 2006) e latino-americanos (Mignolo, 2011), que também desestabilizam e reforçam a radicalização da negação da face racialista do capitalismo modernista (Melamed, 2011) e, correspondentemente, a rearticulação do historicismo discriminatório anti-antiamericanismo em consumerismo pelo NCG. Em paralelo à consolidação do antiamericanismo na principal corrente ideológica no mundo (e.g., Tamames, 2005) - apesar da ausência de consenso sobre o conceito de americanismo em si (Friedman, 2012), observamos a renovação de mecanismos antiemergência e antiantiamericanismo no contexto pós-9/11 do neoliberalismo imperial (Pieterse, 2011) em transição para o autoritarismo populista da hegemonia branca (Peters, 2018). Constituído basicamente por diversos tipos de consumerismo político informados pelo individualismo neoliberal e discursos corporaçõessociedade, o NCG desestabiliza e reforça a negação da face racialista do capitalismo consumerista. Esse quadro vem sendo impulsionado por instituições de governança global e por desenvolvimentos sem precedentes entre o campo de organizações e gestão $(\mathrm{O} \& \mathrm{G})$ e a área de marketing (Micheletti, Follesdal, \& Stolle, 2006; Micheletti \& Stolle, 2012).

Um dos focos prioritários do NCG são os países dos BRICS (iniciais de Brasil, Rússia, Índia, China e África do Sul). Assim como o movimento consumerista nos EUA nos anos 1960-1970 buscava se apropriar da ascensão de minorias políticas constituintes de um mundo emergente globalizante e contê-las, esses países emergentes, crescentemente interconectados entre si e com sociedades emergentes do centro e da periferia do sistema mundo, têm sido avaliados, nos EUA, tanto como fonte de alternativas para um mundo pós-eurocêntrico quanto como séria ameaça não liberal ao planeta e civilização ocidental (Lieber, 2008; Pieterse, 2011). A literatura de NCG reforça o discurso antiantiamericanismo de que países dos BRICS mobilizam movimentos anticonsumerismo e antiamericanismo ao mesmo tempo em que se beneficiam da modernidade global liderada pelos EUA, para promoverem padrões irresponsáveis e populistas de consumismo com crescente impacto global (e.g., Kivenzor \& Spohn, 2016). Esses excessos são tidos como manifestações bárbaras que colocam em risco o progresso da história global (e.g., Varul, 2013). A face neocolonial do NCG (ver Faria \& Hemais, 2017) é ilustrada pela ascensão de literatura corporações-sociedade anti-irresponsabilidade, focada em economias emergentes prescrevendo, por um lado, estratégias corporativas de responsabilidade social e de gestão da pobreza (Porter \& Kramer, 2011), e, por outro lado, institucionalização de consumo ético, sustentável ou consciente de indivíduos (Kharas, 2010). O NCG reforça o mito eurocêntrico liberal do consumidor não gerenciável (Gabriel \& Lang, 2006) e discursos corporações-sociedade que negam a face racialista do capitalismo modernista e o "relacionamento complexo entre racismo e consumerismo" nos EUA (Orser, 1998, p. 664).

Além do racialismo camuflado, que impulsiona debates corporações-sociedade em O\&S nos EUA (Barley, 2010), defensores do NCG negam a eventual cumplicidade do campo com essa transição da globalização neoliberal para uma era de autoritarismo populista (Fotaki \& Prasad, 2015; Murphy \& Willmott, 2015). Em suma, o NCG reativa dinâmicas de apropriação e contenção de mundos emergentes em nome de um mundo global pós-colonial e pós-racista, marcado pela ascensão de riscos e viradas discriminatórias (Beck, 2002).

Em paralelo a rearticulações oligárquico-populistas anti-antiamericanismo, o antiamericanismo tem sido tratado, no pós-9/11, na Europa, como anti-american century (Krastev \& Mcpherson, 2007), e "mais massivo que qualquer outro movimento social na história" (Tamames, 2005, p. 33), e, ainda, como 
sinônimo de terrorismo global nos EUA (Ajami, 2003). Influenciados por esse quadro complexo e por críticas à crescente americanização do campo de $O \& G$ na Europa, autores críticos euro-britânicos apontaram no início dos anos 2000, sob uma perspectiva universalista o antiamericanismo, o ahistoricismo como principal problema da literatura de O\&G (Clark \& Rowlinson, 2004), assim como o marketing (Tadajewski, 2008). Em paralelo, autores de países emergentes da América Latina abraçaram uma perspectiva histórica anticolonial de longa duração para destacar como principal problema a radicalização da colonialidade racialista inaugurada em 1492 nesses dois campos do conhecimento na era do capitalismo neoliberal global comandado pelos EUA (e.g., Firat, 2010; Ibarra-Colado, 2006). Nesse quadro de dicotomizações e ausência de diálogo crítico transmoderno entre esses historicismos, o antiamericanismo impulsiona a rearticulação de dinâmicas anti-antiamericanismo, tidas como antidiscriminatórias, focadas em populismos e identidades essencialistas de povos de mundos emergentes (James, 2011). Em resumo, esses historicismos mobilizados por autores euro-britânicos e da América Latina (sendo esse último classificado pelo primeiro como a-historicismo ou historicismo bárbaro) desestabilizam e reforçam um padrão civilizacional que informa a literatura amnética discriminatória de marketing sobre consumerismo e sua rearticulação contemporânea pelo NCG.

O principal objetivo desse artigo é re-historicizar o movimento consumerista nos EUA por meio de uma perspectiva crítica transmoderna (Dussel, 1994), enunciada em país emergente da América Latina. Indo além das dicotomizações historicismo versus a-historicismo, consumerismo versus anticonsumerismo, e americanismo versus antiamericanismo, recuperamos bases para um NCG alternativo e um campo de O\&G efetivamente global menos subordinado a dinâmicas oligárquicoracialistas. Por meio do reconhecimento da face racialista do capitalismo modernista e do consumerismo, engajamos mundos emergentes em escala global para a promoção de alternativas ao avanço de desigualdade, injustiça e discriminação no contexto do capitalismo neoliberal global em transição para o autoritarismo populista da supremacia branca (Peters, 2018).

Historicizamos consumerismo como movimento multifacetado e multi-identitário - ao invés de um movimento progressista civilizatório que reduziu assimetrias entre vendedores e compradores por meio de uma revolução corporativa que superou dicotomizações corporações-sociedade do passado (Kotler \& Zaltman, 1971), coconstruído por mundos emergentes interconectados. Sob uma perspectiva que vai além de dicotomizações que desestabilizam e reforçam a face racialista do capitalismo e do consumerismo, argumentamos que o NCG obstrui, ao mesmo tempo que possibilita, a recuperação de historicismos e identidades discriminadas no campo de O\&G. Nosso foco não são, entretanto, oligarquias racializadas de países emergentes, mas a crescente maioria de racializados mundos emergentes interconectados que resistem e mobilizam alternativas responsáveis em escala global.

O restante do artigo é dividido em mais três seções. A segunda analisa o historicismo amnético discriminatório da área de marketing por meio de uma perspectiva transmoderna enunciada em país emergente da América Latina. A terceira re-historiciza, então, o movimento consumerista nos EUA, em três contextos espaço-temporais ampliados. A quarta, por fim, apresenta as principais contribuições do artigo e suas implicações para o NCG e o campo de O\&G.

\section{De Historicismo(s) versus A-historicismo a Historicismo Amnético Discriminatório}

Dinâmicas corporações-sociedade e historicismos que negam face racialista do capitalismo modernista e discriminam mundos emergentes não são um fenômeno recente (Lohin, 2017). Essas vêm sendo observadas desde a inauguração do capitalismo moderno com a conquista da América em 1492. Esse quadro é ilustrado pelos debates cristianistas protagonizados por Bartolomé de Las Casas, representando a sociedade europeia, e Ginés de Sepulveda, representando a corporação católica, acerca do direito de governar a América. Tais debates acadêmicos acerca do uso ou não da violência colonialista negam a escravidão de sub-humanos locais (Brunstetter \& Zartner, 2011) e discriminações análogas nas metrópoles mobilizadas pela face racialista do capitalismo modernista (Melamed, 2011). Esses debates eram protagonizados por tipos eurocêntricos de catolicismo, em que um representava o 
outro como anticatolicismo, e ambos se uniam contra historicismos e alternativas mobilizados por barbarismos anticatolicismo e antieurocentrismo, em nome da não discriminação e da salvação universalista. A corporação escravista e a sociedade europeia mobilizaram discursos antianticatolicismo para responderem ao risco a-historicista mobilizado por mundos emergentes constituídos pela maioria não branca, inaugurando, assim, os discursos corporações-sociedade discriminatórios, que negam a face racialista do capitalismo modernista. Tais dinâmicas ajudaram a desestabilizar e a reforçar o padrão civilizatório para a minoria por meio da "subjugação do resto de nós" (Winant, 1994, p. 62). Por exemplo, a face racialista civilizacional do capitalismo consumerista nos EUA, negado por marketing e pelo campo de O\&G, foi sucintamente manifestada pelo boxeador negro Larry Holmes, quando afirmou: "eu fui negro, quando era pobre" (Oates, 1987, p. 62), após a épica disputa pelo título na categoria dos pesos-pesados em 1982, contra Gerry Cooney, desafiante suportado pela América Branca e pela Casa Branca (Acevedo, 2012; Althouse, 2007).

Enquanto consumerismo tornou-se sinônimo de americanismo no pós-Segunda Guerra, na Europa e no Terceiro Mundo (Stephan, 2005), por meio, por exemplo, da institucionalização de debates corporações-sociedade como sinônimo de desenvolvimento pelo campo de $\mathrm{O} \& \mathrm{~S}$, anticonsumerismo tornou-se sinônimo de antiamericanismo e resistência ao desenvolvimento (Gienow-Hecht, 2006). Anticonsumerismo e antiamericanismo, enunciados no Terceiro Mundo, foram tratados como manifestações típicas dos povos sem história que obstruem o progresso por meio de historicismos bárbaros (D. W. Noble, 2002). Com a globalização do antiamericanismo no pós-9/11, impulsionada pelo pronunciamento do presidente George W. Bush - "if you are not with us, you are against us" - que reativou o racialismo enunciado no início dos anos 1990 pela tese do choque de civilizações (Huntington, 1993, p. 27) e pelo projeto neo-imperialista New American Century, da supremacia branca (De Genova, 2010), aquele padrão civilizacional foi rearticulado em anos recentes (Crockatt, 2003). Por exemplo, a cidadania ativista engajada com movimentos contra-hegemônicos vinculados a mundos emergentes e antirracismo nos EUA passou a ser classificada pelo anti-antiamericanismo como "não somente antinacionalista, mas também uma ameaça à segurança da nação" (Schueller, 2007, p. 49, tradução nossa).

Ignorando tais dinâmicas, autores críticos euro-britânicos abraçaram discretamente o antiamericanismo pós-9/11 para propor uma virada histórica no campo de O\&G (Clark \& Rowlinson, 2004), a fim de enfrentar o presentismo e o universalismo radicalizados pela globalização do campo pelos EUA, analisada como Americanização por historiadores na Europa (e.g., Kieser, 2004) e imperialismo disfarçado por autores decoloniais na América Latina (Ibarra-Colado, 2006). Tendo em vista sua vinculação histórica ao americanismo imperialista, segundo autores de mundos emergentes (Dholakia, Firat, \& Bagozzi, 1980), marketing foi pioneiro em abraçar essa virada euro-britânica antiamericanismo (Tadajewski, 2008; Tadajewski \& Sarens, 2008).

Tais dinâmicas, que informam o poder crescente do capitalismo autoritário e da supremacia branca, informam também a institucionalização de discursos corporações-sociedade (mainstream e crítica) que negam a face racialista do capitalismo modernista e a identidade elitista, branquista e masculinista dominante no campo de O\&G (B. Westwood, Jack, \& Frenkel, 2014; R. Westwood \& Clegg, 2003). Assim como críticas desestabilizam e fortalecem o mainstream no âmbito corporaçõessociedade, esses antiamericanismos desestabilizam e reforçam o anti-antiamericanismo mobilizado pela supremacia branca, por meio de dinâmicas de apropriação e contenção. Enquanto a virada histórica euro-britânica vem sendo incorporada pelo projeto estadunidense de globalização do campo, a virada latino-americana vem sendo virtualmente negada (e.g., Firat, 2010; Ibarra-Colado, 2006; Sauerbronn \& Faria, 2009). Essas dinâmicas têm ajudado a permitir, e também a restringir, alternativas para atenuar o avanço do autoritarismo populista mobilizado pela supremacia branca e respectivos antiantiamericanismos (Hartman, 2015). Enquanto essa dicotomização entre anti-americanismo bárbaro e antiamericanismo eurocêntrico historicista ajuda a desafiar a negação da face racialista do capitalismo, também ajuda a promover a radicalização do padrão civilizacional anti-antiamericanismo e a discriminação de mundos emergentes interconectados.

Sob uma perspectiva transmoderna, que não nega a face racialista do capitalismo modernista, tampouco as dinâmicas envolvendo historicismos antiamericanismo enunciados por euro-britânicos e 
latino-americanos, argumentamos que a literatura de O\&G nos EUA não ignora todos os passados (e.g., Weatherbee, Mclaren, \& Mills, 2015). Notadamente no âmbito da educação, O\&S não é exatamente ahistoricista, mas sim seletivamente historicista (B. Westwood et al., 2014); esse padrão amnético discriminatório anti-antiamericanismo informa o passado do consumerismo enunciado pela disciplina de marketing.

Como constituinte atípico e crucial do campo de $O \& G$, a disciplina de marketing continua sendo criteriosa na escolha de quais passados relembrar e de como relembrá-los. Enquanto alguns discursos, eventos e literaturas são "ativa e deliberadamente esquecidos" (Patterson, Bradshaw, \& Brown, 2008, p. 451, tradução nossa), outros constituem o historicismo amnético, que nega identidades discriminadas por O\&S e a face racialista do capitalismo modernista. O NCG focado em sociedades emergentes dos BRICS, renova e amplia o historicismo amnético do consumerismo.

As críticas do antiamericanismo ao a-historicismo dominante no contexto do capitalismo neoliberal global rearticulam não apenas o excepcionalismo americanista de direita e o padrão civilizacional da supremacia branca (Hodgson, 2004), mas também o argumento de que reviver passados ressaltados por historicismos bárbaros, classificados pelo padrão anti-antiamericanismo como ameaçadores e irresponsáveis (Katzenstein \& Keohane, 2007), é uma irresponsabilidade que bloqueia o progresso natural do conhecimento acadêmico (Brownlie \& Saren, 1995) e cede ao padrão histórico de contramovimentos ambivalentes de mundos emergentes que se beneficiam da modernidade e promovem "a rejeição da ciência, tecnologia, e vida urbana ... o desgosto generalizado com modernidade, a defesa de meios tradicionais de vida, e a condescendência cultural das elites" (Hollander, 1995, p. 384, tradução nossa).

Críticas do antiamericanismo radicais são encorajadas e atribuídas a mundos emergentes dominados por oligarquias populistas irresponsáveis; tais dinâmicas têm sido instrumentais para, por um lado, confirmar a excepcionalidade do liberalismo dos EUA e da supremacia branca (Hodgson, 2004) por não discriminar até mesmo críticas motivadas por inveja e ressentimento, e, por outro lado, justificar a mobilização de dinâmicas anti-antiamericanismo de contenção ou restrição pela supremacia branca. Em países emergentes, o historicismo amnético discriminatório do NCG tem sido tanto reforçado (Rahman, 1994; Rocha, 2000) quanto desestabilizado por historicismos que problematizam a face racialista do capitalismo e consumerismo (Varman \& Sreekumar, 2015); ambos são eventualmente classificados como constituintes de dinâmicas contra hegemônicas de mundos emergentes pelo liberalismo de restrição ou contenção, subordinados ao anti-antiamericanismo civilizacional.

Segundo teorias dominantes de relações internacionais (RI), cujo campo de conhecimento e práticas é comandado por elites dos EUA vinculadas à supremacia branca (Vitalis, 2000), hegemonias imperiais devem promover contra hegemonia interna para se defenderem de dinâmicas contrahegemônicas irresponsáveis mobilizadas por mundos emergentes: "uma hegemonia racional deve engajar um grau institucional de autorrestrição e auto-vinculação, a fim de rebaixar a percepção de ameaça que outros têm da hegemonia" (Hurrell, 2006, p. 5, tradução nossa). Tais dinâmicas são cada vez mais necessárias e desafiantes devido à mobilização de dinâmicas similares por países dos BRICS, em especial a China (Lieber, 2008). Assim como anticristianismo vem sendo mobilizado sob diferentes perspectivas desde 1492, antiamericanismos vêm sendo mobilizados desde o final do século XIX, tanto por forças populistas em diferentes partes do mundo, em especial nos EUA, quanto pelo esnobismo europeu de ordem intelectual ou de classe - classificados nos EUA como compreensível mistura de "admiração, inveja e ressentimento" (Nye, 2004, p. 38) - em resposta à combinação notadamente desproporcional de cultura popular/populista e poderio político-econômico-militar dos EUA. Segundo a literatura de RI, a mobilização de antiamericanismo por europeus e países emergentes dos BRICS é "estrutural... os Estados Unidos são o big kid on the block e a desproporção produz uma mistura de admiração, inveja e ressentimento" (Nye, 2004, p. 38, tradução nossa). Obviamente, os segundos são bem mais ameaçadores do que os primeiros. Especialmente no pós-9/11, qualquer poder emergente propondo resistir "à ordem liberal [passou a] ser classificado junto a regimes rebeldes e a inimigos de liberdade econômica e política" (Hurrell, 2006, p. 7, tradução nossa). Por exemplo, historicismos seletivos mobilizados por mundos emergentes que promovem a conflação de globalização e 
americanização sob uma perspectiva anti-imperialista populista são tidos como irresponsáveis pela supremacia branca (Hage, 2012) e por praticantes-teóricos dos liberalismos de contenção e de restrição: "globalização é mais do que americanização, mas para ativistas do movimento antiglobalização que querem resistir ou remoldar globalização, antiamericanismo costuma ser uma arma útil" (Nye, 2004, p. 42). Mundos emergentes continuam sendo induzidos a mobilizarem anti-americanismos radicais. Historicismos antiamericanismo enunciados por autores da América Latina contribuem para que mundos emergentes sejam classificados, especialmente no que tange aos BRICS, de stakeholders irresponsáveis antiliberalismo (Patrick, 2010) pelo anti-antiamericanismo mobilizado pelos liberalismos de contenção (Bello, 1994) e restrição (Nagel, 2005). Por meio de uma perspectiva crítica transmoderna (Dussel, 1994), que vai além dessas dicotomizações e dinâmicas correspondentes, rehistoricizamos o consumerismo nos EUA para promover alternativas em O\&G e NCG.

\section{Historicizando o Consumerismo sob uma Perspectiva Transmoderna}

Passados do consumerismo negados pela disciplina de marketing vêm sendo historicizados nos EUA por diferentes áreas, tais como História, Economia Política e Ciência Política. Essa literatura, recuperada aqui por meio de um historicismo transmoderno enunciado em país emergente da América Latina que reconhece dinâmicas racialistas de apropriação e contenção de mundos emergentes pelo padrão civilizacional dominante, aponta que o consumerismo nos EUA é constituído por três eras interconectadas (Cohen, 2003; Tiemstra, 1992): a primeira, durante a Era Progressista, de 1887 a 1914; a segunda, na Era do New Deal, de 1927 a 1939; e a terceira, denominada de New Frontier, de 1962 a 1978. A área de marketing se restringe à terceira, por sua suposta proeminência em relação aos outros passados relativos ao binômio corporação-sociedade (Day \& Aaker, 1970; Kotler, 1972).

\section{Primeira era (de 1887 a 1914)}

Os anos 1890, no contexto da Era Progressista, marcaram uma virada histórica importante para os discursos oligárquicos corporações-sociedade e historicização anti-antiamericanismo do consumerismo. Historiadores estadunidenses influentes interpretaram a emergência do industrialismo capitalista como tanto falecimento (Turner, 1921) quanto com nascimento (Beard, 1924) da democracia e do americanismo. Similar ao debate acadêmico entre Las Casas e Sepúlveda no século XVI, cada vertente era classificada pela outra como antiamericanismo, enquanto ambas se juntavam na negociação da face racialista do capitalismo e no ofuscamento de historicismos alternativos e alternativas ao historicismo hegemônico. Por meio de dinâmicas de apropriação e contenção de alternativas mobilizadas por mundos emergentes - em especial a Alemanha (Conrad, 2010), o americanismo nacionalista foi então substituído pelo internacionalista. A inauguração dessa Era foi então marcada pelas expulsões dos britânicos na Venezuela, em 1895, e da Espanha de Cuba e Porto Rico, em 1898, pela supremacia branca internacionalista apoiada por forças econômico-militares dos EUA, antes da tomada do Caribe (McPherson, 2009). Tal virada marcou a derrota do capitalismo oligárquiconacionalista e o triunfo internacionalista da democracia industrial dos países desenvolvidos (Beard, 1924).

Dinâmicas oligárquicas focadas em democracia e mercado nos EUA, então, foram protagonizadas por grandes corporações e maiorias políticas vinculadas à supremacia branca - representadas por "manufatureiros, banqueiros, fazendeiros, trabalhadores e reformistas... e [envolvendo] tanto diversas fontes da burguesia no mercado quanto intelectuais, reformistas sociais, sindicalistas, e líderes políticos das várias correntes pró-corporação, populista, progressiva e socialista" (Sklair, 2011, p. 17, tradução nossa) - unidas contra um passado selecionado e poderes emergentes antiamericanismo europeus e não europeus.

Essa virada reforçou e desestabilizou o americanismo, ao opor-se à grande crise sócio-política e moral do americanismo nacionalista do passado, marcado pela guerra com o México, pela guerra civil entre Norte e Sul, e pelo extermínio de nações indígenas durante o século XIX (Beard, 1924). 
Historicismos antiamericanismo mobilizados por mundos emergentes que problematizavam a face racialista do capitalismo foram ofuscados pelo americanismo internacionalista, por meio da mobilização de dinâmicas anti-antiamericanismo.

As fusões entre empresas nos EUA, vinculadas a esse novo americanismo antiamericanismo, impulsionaram o expansionismo do capitalismo corporativo e profundas transformações sociais domésticas - sem guerras ou revoluções internas, diferentemente do passado do americanismo nacionalista - e internacionais - com as necessárias intervenções em mundos emergentes, que supostamente fomentavam revoluções antiliberdade e antidemocracia irresponsáveis. Dentre as intervenções internacionalistas na América Central, com suporte de corporações modernas e da sociedade liderada pela supremacia branca - descrito por Harvey como "uma forma de dominação sem colônias" (Harvey, 2007, p. 32) forjada por uma tradição imperial que nega a face racialista do capitalismo (Melamed, 2011), destacam-se a invasão da Nicarágua, junto com as forças britânicas em 1898; a supressão da Rebelião Boxer na China, e as diversas intervenções na Colômbia e no Panamá, todas em 1900; na República Dominicana, em 1903 e 1904; em Cuba, em 1906-1907; em Honduras, em 1907 e 1911; na Nicarágua novamente em 1910 e, posteriormente, de 1912 a 1925 (Seymour, 2012).

O sistema ferroviário e a infraestrutura de comunicação com alcance nacional protagonizados por corporações que lideravam nos EUA a democracia industrial dos países desenvolvidos alimentaram o perfil populista-consumerista dessa nova era. A queda de investimentos estrangeiros e a falência generalizada de empresas, no início dos anos 1890, resultaram na sobrecarga de bancos, fragilização aguda de minorias políticas, e ascensão do capitalismo financeiro (Markin, 1971). Liderado pelas grandes ferrovias, tidas como organizações quase-públicas de regime de mercado administrativo que superaram os antagonismos corporações-sociedade do passado (Baskin, 1988), os valores West Point foram substituídos pelos de Wall Street, que se tornou instituição central da democracia consumerista de mercado (Shulman, 2000). Em 1897, com a retomada dos níveis de preços e consumo, desconfianças quanto ao poder empresarial mobilizadas por mundos emergentes que problematizavam a face racialista do capitalismo progressista foram atenuadas pelo sistema oligárquico-populista de propriedade pública de corporações e desenvolvimentos tecnológicos e de comunicação de massa, liderados pela oligarquia beneficiária do regime de mercado administrado (D. F. Noble, 1979).

As reações antiamericanismo da Europa (Conrad, 2010) - em paralelo a movimentos anticolonialismo na África e antiamericanismos bárbaros (Ceaser, 2003) - estimularam novas dinâmicas corporações-sociedade anti-antiamericanismo, com destaque para intervenções pró-corporação no sistema jurídico nacional. Essas institucionalizaram o regime de mercado administrado e os discursos corporação-sociedade baseados na identidade discriminatória rapidamente incorporada pelo nascente campo de O\&G nos EUA (Perrow, 2002).

Os investimentos corporativos em tecnologias de produção em massa, necessários para esse americanismo internacionalista baseado na emancipação do indivíduo (branco) livre via consumo e mobilizados por oligarquias de Wall Street e governo federal, suprimiram alternativas comunitaristas de capitalismo e consumerismo mobilizadas por indivíduos e grupos racializados de mundos emergentes interconectados. O regime de mercado administrado, com suporte de discursos corporações-sociedade que ressaltavam o novo excepcionalismo, substituiu gradualmente o regime de mercado concorrencial celebrado pelo americanismo nacionalista, permitindo que grandes corporações expandissem seus domínios territoriais e correspondentes privilégios em nome da sociedade (Herrmann, 1982), ao mesmo tempo que ocultavam a subordinação desse expansionismo à supremacia branca. Em 1910, por exemplo, os EUA já eram os principais compradores do café brasileiro, e o Caribe fora transformado em um "lago americano" (Goldfrank, 1975, p. 422, tradução nossa). Além de promover a aceitação do princípio oligárquico-populista de que todos se beneficiariam de grandes corporações administradas profissionalmente, em um contexto de negação de direitos a minorias políticas e raciais vinculadas a mundos emergentes, o americanismo internacionalista marcou uma grandiosa ascensão do poder político-econômico-cultural de grandes corporações (Tiemstra, 1992) e a institucionalização da negação da face racialista do capitalismo também no campo de O\&G. 
Essa virada histórica do capitalismo corporativo nos EUA rearticulou dicotomizações historicismo versus a-historicismo e americanismo versus antiamericanismo na Europa. Werner Sombart, por exemplo, desafiou esse novo americanismo, ao decretar, em 1904, a impossibilidade de existência de socialismo nos EUA, devido à hegemonia do excepcionalismo americanista e correspondente prevalência do a-historicismo no país (Sombart, 1976). Esse historicismo antiamericanismo europeu ofuscou mundos emergentes, também negou a face racialista do capitalismo, inaugurados por conquistadores eurocêntricos e modernidade universalista em 1492 (Dussel, 1994).

Novas restrições governamentais foram criadas, com o propósito de proteger o cidadão como consumidor - em resposta, por exemplo, a contramovimentos mobilizados por trabalhadores e minorias políticas não brancas - dos riscos inevitáveis gerados pelo avanço do capitalismo corporativo na Era Progressista. O fortalecimento institucional do mercado de ações, que tornava pública a grande corporação moderna em consonância com debates corporações-sociedade da época (Baskin, 1988), ofuscava dinâmicas de privilégios e opressões que constituíam o regime de mercado administrado e também as intervenções imperialistas promovidas por Theodore Roosevelt (1901-1909), que informaram a revolução mexicana de 1910 (Goldfrank, 1975). A rearticulação da Doutrina Monroe (enunciada nos anos 1820) nessa Era Progressista, refletiu "a confiança e a presunção dos governantes de uma potência emergente" (Livingstone, 2009, p. 13, tradução nossa). Destaca-se, por exemplo, a criação, em 1914, do Federal Trade Commission Act (Cohen, 2003).

Juntamente à criação das primeiras escolas de negócios dos EUA - Wharton School, em 1881; Haas School of Business e The Booth School of Business, em 1898; Tuck School of Business, em 1900; Kellog School of Management e Harvard Business School, em 1908, e Babson School, em 1919 -, surgiram as primeiras organizações de defesa do consumidor, a partir da National Consumers' League, fundada em 1898. Em resposta à exploração de trabalhadoras denunciada pela Working Womens Society, de Nova Iorque, em 1888, cuja prominência ajudava a invisibilizar movimentos pró-trabalhadores e antirracismo classificados sumariamente como antiamericanismo, a Consumer's League, de New York foi criada em 1891, fomentando a ideologia de República de Consumidores (Cohen, 2003), baseada na provisão de informação a consumidores sobre quais lojas tratavam de forma justa seus empregados.

Por meio da explosão "de atividades reformistas organizadas por mulheres na Era Progressista" (Storss, 2000, p. 15, tradução nossa), que indiretamente ajudavam a oprimir mulheres negras e afroamericanas, ativistas defendiam que o capitalismo corporativo não deveria privilegiar a oligarquia dos EUA, tampouco ser destronado pelo comunismo anti-americanismo ou outras modalidades de antiamericanismo bárbaro (Seymour, 2012). Deveria, sim, gerar benefícios à maioria, segundo os fundamentos elitistas e racistas do novo americanismo, que também informava a identidade dominante das primeiras escolas de negócio (Cohen, 2003; Pfeffer, 2008). Com crescente apoio acadêmico, esse movimento consumerista tornou-se nacional com base no motto investigar, agitar, legislar, que ajudava a invisibilizar as faces racialistas do capitalismo, do consumerismo e da sociedade corporativa. Apelos populistas pró-consumidor, que ajudaram a ofuscar e legitimar intervenções civilizatórias no país e no exterior, apropriando-se e contendo alternativas e identidades mobilizadas por mundos emergentes, foram abraçados por políticos, partidos políticos e grandes escolas de negócios. Essas maiorias políticas defendiam a causa consumerista e garantiam a legitimidade de grandes corporações, organizações consumeristas e das principais escolas de negócios (Tiemstra, 1992).

Além de constituírem o regime de mercado administrado e o americanismo internacionalista/expansionista, e ajudarem a moldar a identidade discriminatória das escolas de negócios e da chamada sociedade corporativa (ver Dijk, 1993), organizações consumeristas ajudaram a criar regulações oligárquico-populistas que desestabilizavam e reforçavam a legitimidade ampliada das corporações modernas e oligarquias corporativas (Kolko, 1963). Um exemplo é a Pure Food and Drug Act, criada em 1906, que, entre outras atribuições, regularia a indústria de carnes para supostamente proteger consumidores (Herrmann, 1982). Também constituintes desse contramovimento, o antiantiamericanismo, o campo de $\mathrm{O} \& \mathrm{G}$ e a literatura de marketing representavam governo e empresas como forças antagônicas e independentes - seguindo o excepcionalismo baseado no mito de balanço de poderes - para justificar e promover os discursos corporações-sociedade que representavam o consumidor individual como poder soberano e também a identidade consumerista oligárquico-populista 
das escolas de negócios. Mais do que uma preocupação com obtenção de lucros, a prioridade da elite oligárquica, branquista e masculinista da Era Progressista era "moldar a sociedade" (Tiemstra, 1992, p. 8, tradução nossa) por meio principalmente da apropriação e da contenção de movimentos sociais (Nadel, 1971; Rotfeld, 2010) e também de contramovimentos que eram frequentemente classificados como antiamericanismos.

\section{Segunda era (de 1927 a 1939)}

Novas fusões empresariais, implementadas nos anos 1920, informadas pela radicalização do americanismo internacionalista após a revolução soviética e a Primeira Guerra Mundial, marcaram o surgimento da segunda era de consumerismo. Incentivadas pelo mercado de ações e impulsionadas por discursos corporações-sociedade e falhas nas leis antitruste, tais fusões consolidaram a institucionalização de oligopólios industriais no país (Tiemstra, 1992). No começo dos anos 1930, a proteção do consumidor foi, então, institucionalizada em nível nacional com a proliferação das organizações especializadas (Glickman, 2009), que mantiveram a negação da face racialista do capitalismo e o consumerismo.

O mercado livre voltava a ser prezado pela sociedade, enquanto o mercado administrado enfrentava críticas crescentes, informadas por novos discursos e debates corporações-sociedade que ofuscavam outros debates e alternativas mobilizados por mundos emergentes. Com apoio institucional de organizações consumeristas e escolas de negócios, defendia-se um nível mais elevado de proteção do consumidor contra produtos polêmicos e informações equivocadas fornecidas por empresas (Rotfeld, 2010). Para conter a emergência de socialismo de estado e antiamericanismos correspondentes, que ficaram particularmente intensos com o isolacionismo que informou a saída dos EUA da Europa em 1918, a ênfase do movimento passou a ser a educação de consumidores, com base no argumento crítico de que empresas não informavam o que organizações consumeristas julgavam ser o necessário (Glickman, 2009). Dentre essas organizações, destaca-se a Consumers' Research (CR), criada em 1929, com o objetivo de suprir informações técnicas sobre produtos e gerar consciência pública sobre a qualidade dos bens, impulsionada por dinâmicas protagonizadas pelo americanismo internacionalista anticomunista e antiestatista.

A quebra da bolsa de Nova Iorque, em 1929, alavancou o início de mudanças regulatórias que rearticularam, nos anos 1930, a legitimidade de grandes empresas no contexto de depressão econômica. Sob uma perspectiva renovada de americanismo, que se apropriava de ativismos mobilizados por mundos emergentes com novos discursos corporações-sociedade celebrando o consumidor ativista e o continha (Creighton, 1976), além do gestor profissional responsável (Bendix, 1956) e das organizações consumeristas especializadas (Tiemstra, 1992). Por exemplo, em 1935, já durante o New Deal de Franklin Roosevelt, a CR contava com mais de cinquenta mil assinantes de sua revista (Donohue, 2010). Tendo em vista muitas críticas com respeito às limitações do consumerismo, alguns líderes dissidentes da CR fundaram, em 1936, a Consumers Union (Hilton, 2009). A CU, radicalizando a apropriação e a contenção de movimentos contra-hegemônicos e alternativas mobilizadas por mundos emergentes, veio a substituir a CR como principal organização consumerista, mantendo o foco em teste de produtos e incluindo matérias sobre condições de trabalhos e alianças políticas (Mayer, 1989).

Frente à crise do fascismo e do nazismo na Europa e às primeiras crises imperiais enfrentadas por potências colonialistas na África, que, em conjunto, impulsionavam o comunismo e movimentos sindicais no país (Glickman, 2009), assim como dinâmicas anti-antiamericanismo, foram então criadas instituições para representação política do consumidor - ofuscando alternativas de consumerismo nos EUA e em detrimento de trabalhadores e outras minorias políticas também mobilizadas por mundos emergentes - no âmbito do governo federal dos EUA. Destacam-se a Consumer Advisory Board, como parte do National Recovery Administration (NRA), e o Consumers' Council. Ambos defendiam um controle não estatista do governo sobre a economia, em nome da sociedade, de acordo com fundamentos anti-antiamericanismo do New Deal (Mayer, 1989). Visto que essa era tinha como principal característica consolidar o americanismo internacionalista em contexto de crise profunda no país e na Europa sob uma perspectiva reformista, a cúpula da NRA acabou vetando as posições mais contundentes 
dos ativistas para a resolução dos problemas econômicos nacionais. Consumidores estariam mais protegidos por políticas governamentais que promovessem aumento da produção industrial e lucratividade das empresas (Creighton, 1976), com a disseminação de organizações consumeristas no país e no exterior (Glickman, 2009). O governo dos EUA reforçava as dinâmicas oligárquico-populistas com grandes corporações e consolidava o consumo ativista como primazia segundo a controversa política de consenso (Wall, 2009) informada por dinâmicas de apropriação e contenção de alternativas e identidades mobilizadas por mundos emergentes que problematizavam a radicalização da face racialista do capitalismo e o consumerismo pela face imperial do New Deal.

Embora nas duas primeiras eras do consumerismo o governo dos EUA não pudesse fazer frente às potências europeias quanto aos rumos da história do capitalismo, o controle militar e econômico das Américas Central e Latina, consolidado pelo New Deal, permitiu vincular o consumerismo a um projeto de potência global. Por meio do consumerismo, o governo dos EUA mobilizou discursos corporaçõessociedade sedutores com apelo sócio-desenvolvimentista, que ofuscavam a face imperialista do New Deal. Transformações em mercados nacionais no exterior a partir da difusão do consumerismo oligárquico-populista conectado à revolução neoliberal antiestatismo permitiram aos EUA aumentar sua influência global (Hilton, 2009), desbancando potências europeias no pós-Guerra. Hegemonia dos EUA no âmbito consumerista tornou-se instrumental para conter avanços antiamericanismo em mundos emergentes, especialmente na Ásia e na África, mas também nos EUA e na América Latina.

\section{Terceira era (de 1962 a 1978)}

Segundo o historicismo amnético de marketing, o termo consumerismo foi associado à proteção de consumidores nessa época (Swagler, 1994). Consumerismo foi definido como promoção de equilíbrio de direitos e poderes entre produtores e vendedores por uma revolução sem precedentes do capitalismo estadunidense no âmbito corporações-sociedade (Kotler, 1972). Essa versão nega a existência dos contramovimentos - constituintes do consumerismo nos EUA desde os anos 1890 -, que associavam ativismo consumerista a modalidades alternativas de ismo, tais como comunismo, socialismo e comunitarismo (Mayer, 1989), em contexto acadêmico marcado pelo Macarthismo (Tadajewski, 2006) e por guerras culturais promovidas pela supremacia branca (Allen, 2001), em resposta a múltiplos antiamericanismos mobilizados por mundos emergentes, especialmente a partir do início da Guerra do Vietnam (Dudziak, 2000). A literatura de marketing nega a transformação do campo de $\mathrm{O} \& \mathrm{G}$, em geral, e da disciplina de marketing, em termos específicos, em recursos (geo)políticos durante a Guerra Fria para controlar os significados de consumerismo nos EUA e no exterior.

Cabe destacar, por outro lado, que o historicismo amnético de marketing não ignora autores de outras áreas (Cohen, 2003; Tiemstra, 1992) que apontam como um dos principais eventos dessa era o discurso do Presidente J. F. Kennedy ao congresso dos EUA, em 1962, no qual defende quatro direitos fundamentais do consumidor: (a) informações corretas e completas sobre produtos; (b) produtos seguros em seu uso comum;(c) escolher entre produtos de diferentes especificações; e (d) ser ouvido por órgãos de regulação do governo federal. No auge da Guerra Fria, a mobilização desse discurso corporaçõessociedade pela administração Kennedy permitiu que o campo de $O \& G$ e, mais especificamente, a disciplina de marketing - que era criticada em partes do mundo por sua vinculação a americanismos ou a imperialismo - difundisse globalmente a ideia liberal-expansionista de que grandes corporações deveriam promover o ativismo consumerista em nome da sociedade e democracia. Autores vinculam esse discurso ao movimento pelos direitos civis, negando a face imperial do capitalismo gerencial, segundo os proponentes da revolução neoliberal nascente (Buskirk \& Rothe, 1970). Por exemplo, esse historicismo nega alternativas e identidades não discriminatórias em consumerismo e no campo de $O \& G$ mobilizadas pelo movimento negro nos EUA em conexão com contramovimentos no Terceiro Mundo (Joseph, 2006). Debates, análises e historiografias produzidos por outras áreas que associavam consumerismo à longa duração do movimento black power (Joseph, 2006; Ogbar, 2005), interconectado com movimentos contra-hegemônicos e anticoloniais no exterior (Slate, 2012), foram seletivamente negados pelos renomados historiadores de marketing (Bartels, 1976; Brown, 1995). 
No plano doméstico, os EUA passavam por turbulências revolucionárias nessa era do New Frontier, fomentadas pelos movimentos por direitos civis e justiça racial na sociedade, na academia e política. Com a mobilização radical do padrão civilizacional anti-antiamericanismo, movimentos antirracismo nos EUA foram associados a antiamericanismo, tanto pela esquerda quanto pela direita, a pós-nazismo, e também a fascismo. Defensores do anti-anti-americanismo civilizacional atribuíam às tensões raciais à desagregação violenta da identidade americana [sic] e a divisão discriminatória dos EUA entre América Branca e América Negra pelos proponentes da chamada supremacia negra (Sales, 1994). Dinâmicas anti-antiamericanismo aproximaram consumerismo do movimento de direitos civis (Glickman, 2009; Vogel, 2006), radicalizando a negação da face racialista do capitalismo e do consumerismo e, também, as dinâmicas coloniais de apropriação e contenção de movimentos contrahegemônicos de mundos emergentes que ajudaram a constituir o consumerismo nos EUA desde 1890.

A aproximação entre os movimentos consumerista e de direitos civis constitui uma questão central para o historicismo amnético discriminatório do consumerismo nos EUA. Por exemplo, pesquisadores da área de marketing analisaram a discriminação sofrida por negros e pobres (Ratner, 1968; Sturdivant \& Wilhelm, 1969), sob uma perspectiva corporação-sociedade a-historicista, que consolidava a improvável negação da face racialista do capitalismo e do consumerismo nesse contexto revolucionário do capitalismo. Segundo o historicismo de marketing, endossado imediatamente por escolas de negócios renomadas, discriminação ocorria nas situações de compra em que lojistas vendiam a consumidores negros produtos por preços mais elevados do que quando vendidos a consumidores brancos afluentes (Toyer, 1968). Enquanto analistas defendiam que governos deveriam assumir responsabilidades maiores na administração do mercado (Andreasen, 1975), grandes corporações e escolas de negócios assumiam a responsabilidade no âmbito corporações-sociedade de conduzir, por meio do consumerismo, gestores e sociedade à verdadeira gestão e ao verdadeiro marketing.

Esse historicismo discriminatório, difundido em escala global por grandes corporações e escolas de negócios, ofuscou antagonismos históricos entre empresas e escolas de negócios e minorias políticas não brancas de mundos emergentes nos EUA. A versão de consumerismo do marketing nega debates sobre segregação laboral praticada por corporações industriais e a recusa de estabelecimentos comerciais em atender negros e, especialmente, o aprisionamento e uso de violência contra aqueles que ousassem desrespeitar tais leis, oficializadas por meio de estatutos estaduais e municipais (Pollitt, 1960). Esse cenário era ainda mais grave no sul dos EUA, onde oligarquias brancas locais mais abertamente integravam movimentos discriminatórios radicais, tais como o Ku Klux Klan, e exerciam atividades governamentais, judiciais, comerciais e educacionais (Chalmers, 2003).

A literatura de marketing também nega importantes contribuições de teorias-práticas Terceiro Mundistas à democarcia, ilustrado pela ascensão do ativismo radical mobilizado pelos US Third World Leftists (Young, 2006), e movimentos do Terceiro Mundo que influenciaram lideranças do movimento de direitos civis, as quais mobilizaram teorias e práticas antirracismo e antidiscriminatórias - não apenas no âmbito do consumerismo e da sociedade, mas também da academia - nos EUA (Rollins, 1986).

A disciplina nega a importância dos diferentes tipos de movimentos antidiscriminação por justiça racial para as conquistas do movimento por direitos civis. Por um lado, havia lideranças negras, tais como Martin Luther King, inspirados no ativismo pacifista de Jesus Cristo e Gandhi, que buscavam mudar o status quo por meio de protestos pacíficos e pressionando governantes a aprovarem leis que garantissem igualdade de direitos a negros. O consumerismo alternativo correspondente, não reconhecido por escolas de negócios e negado pelo campo de $\mathrm{O} \& \mathrm{G}$, contemplava boicotes a empresas que não contratavam negros e incentivos a protestos não violentos em estabelecimentos comerciais que se negavam a atendê-los (Glickman, 2009).

Por outro lado, lideranças radicais, tais como Malcolm X e os Black Panthers, defendiam que negros agissem contra a discriminação racial mesmo que tivessem que usar a violência (Sales, 1994). Ativistas radicais viam o acirramento da segregação entre brancos e negros, por meio da mobilização de identidade política em múltiplos contextos de prática, que foi classificada pela sociedade dominante como antiliberalismo irresponsável ou antiamericanismo bárbaro, uma forma de emancipação sóciopolítica de mundos emergentes interconectados. Se, por um lado, a independência de alguns países do 
Terceiro Mundo, tais como Senegal, foi alcançada sem levantes armados, por outro, intelectuais bárbaros, tais como o martinicano Frantz Fanon, defendiam o uso da violência para libertação da opressão de colonizadores europeus (Fanon, 1963), como na Argélia, durante a guerra contra a França, entre 1954 e 1962.

Para a superação, a radicalização da face racialista do capitalismo e consumerismo, nesse contexto histórico, a população negra era incentivada, por exemplo, a consumir em estabelecimentos de propriedade de negros e em bairros de maior concentração negra, com o objetivo de construir um amplo e poderoso mercado exclusivo de/para negros e promover alternativas correspondentes em escala nacional (Cohen, 2003). Essas lideranças radicais também se inspiravam em teorias e movimentos contra-hegemônicos do Terceiro Mundo, iniciados no pós-Segunda Guerra e intensificados nos anos 1960 (Berger, 2004; Varman \& Belk, 2009). Desde a vitória de Fidel Castro na Revolução em Cuba, por exemplo, o governo cubano passou a receber ativistas estadunidenses negros - por vezes, pedindo asilo para escapar das perseguições que sofriam do governo dos EUA, atraídos pelas políticas antirracismo impostas por Castro e por alternativas teórico-práticas correspondentes (Young, 2006).

Esse movimento e a concretização de alternativas correspondentes nos EUA que embasam a perspectiva contemporânea de transmodernidade colonial enunciada na e a partir da América Latina (Dussel, 1994) - originadas em múltiplos passados da colonialidade duradoura, formalizadas no pósSegunda Guerra, com a gradual ascensão do Terceiro Mundo, intensificadas nos anos 1960 com o início do ocaso da hegemonia dos EUA, e consolidadas com a constituição de mundos emergentes interconectados em escala global no pós-1968 - foram tidos por círculos conservadores vinculados à supremacia branca e a lideranças neoliberais em formação como a ameaçadora terceira força global, capaz de obstruir a hegemonia ocidental dos EUA (Patel \& Mcmichael, 2004).

O consumerismo amnético de marketing nega esse lado da história e as múltiplas transmodernidades correspondentes que constituem o movimento por direitos civis nos EUA e, também, o movimento consumerista e suas alternativas. Nos anos 1970, a Nova Direita (New Right) associada à revolução neoliberal de acumulação via despossessão (Harvey, 2007) ajudou a desestabilizar e a reforçar esse historicismo discriminatório por meio de uma defesa fundamentalista mercado-cêntrica dos direitos de indivíduos no livre mercado (Hall, 2005; Vogel, 2006).

A contrarrevolução neoliberal, iniciada formalmente nos anos 1960-1970, foi abraçada pela hegemonia branca dos EUA com base no argumento politicamente correto de que "o clima antiempresas e anti-imperialista que emergiu no final dos anos 1960 havia ido longe demais" (Harvey, 2007, p. 30). Essas lideranças germinaram em think tanks neoliberais e escolas de negócios, discursos corporaçõessociedade antiestatismo e anticomunitarismo que negavam "a complexidade e o dinamismo do movimento, seu crescente foco na desigualdade estrutural, e seus objetivos 'radicais de reconstrução"" (Hall, 2005, p. 1237, tradução nossa), criando e rearticulando historiografias oligárquico-populistas, com apelo nacional e global, que se conformavam aos valores da classe-média branca e da meritocracia individualista liberal, por meio de dinâmicas de apropriação e contenção de mundos emergentes.

Conservadores do New Right apropriaram e contiveram contramovimentos e alternativas que desafiavam a face racialista do capitalismo modernista e do consumerismo, historicamente negada por discursos corporações-sociedade mobilizados pelo campo de $O \& G$ em escala global. A negação do direito de consumo livre, sob a perspectiva responsável de consumerismo gerada por uma nova revolução corporações-sociedade, era descrita como uma violência antiamericanismo discriminatória aos princípios de livre mercado e à democracia enunciadas pela revolução neoliberal (Cohen, 2003).

Essa versão discriminatória de movimento consumerista se consolidou após Ronald Reagan assumir a presidência dos EUA, em 1980, com uma grandiosa desregulamentação oligárquico-populista do mercado em nome do modelo consumerista corporações-sociedade (Cohen, 2003), com base no princípio de que o que era bom para empresas, era bom para os EUA. Prometendo que o capitalismo neoliberal global resultaria em liberdade e prosperidade a todos (Harvey, 2007), por meio da mobilização de orientação neoliberal belicosa ampliada (Faria \& Hemais, 2017), foi negada a possibilidade de debates vinculados ao passado e mundos emergentes que viessem a dividir novamente 
os EUA e obstruir o progresso da história global. Conservadores adotaram políticas populistas extremas para bloquear a eventual recuperação de tais movimentos e historicismos, institucionalizando, com suporte da academia neoliberal, o mais baixo nível de uso de políticas sociais em comparação com as seis administrações precedentes (Amaker, 1988) e impulsionando a emergência de múltiplas alternativas antidiscriminatórias em mundos emergentes interconectados. Isso informa o contexto contemporâneo do capitalismo neoliberal global em transição para o autoritarismo populista da hegemonia branca (Peters, 2018) e o NCG focado em países dos BRICS.

\section{Considerações Conclusivas}

Em resposta ao avanço da desigualdade, da injustiça e da discriminação no contexto do capitalismo neoliberal global em transição para o autoritarismo populista da supremacia branca e à radicalização da negação da face racialista do capitalismo modernista pelo NCG focado em mundos emergentes (a partir) dos BRICS, re-historicizamos neste artigo o movimento consumerista nos EUA, por meio de uma perspectiva crítica transmoderna. Enunciada em país emergente da América Latina, essa perspectiva vai além dos excessos informados pelas dicotomizações historicismo versus ahistoricismo, consumerismo versus anticonsumerismo, e americanismo versus antiamericanismo, para superar o anti-antiamericanismo civilizacional que informa o historicismo amnético sobre consumerismo produzido por marketing e pelo campo de O\&G. Recuperamos, do passado negado por marketing e $\mathrm{O} \& \mathrm{G}$, múltiplas alternativas de consumerismo, mobilizadas por mundos emergentes, que problematizam a face racialista do capitalismo modernista para propormos alternativas em NCG que sejam relevantes para a maioria.

Essa virada histórica transmoderna é proposta em um contexto de transição do capitalismo neoliberal global para o populismo oligárquico, no qual mundos emergentes continuam mobilizando alternativas para o NCG e O\&G, tais como: Black Lives Matter - movimento ativista internacional, surgido nos EUA em 2013, que desafia abusos de violência contra negros por parte do Estado ou por grupos e organizações vinculados à supremacia branca (Edwards \& Harris, 2016); Occupy Wall Street e Occupy Everywhere - movimentos de (re)ocupação de espaços públicos e promoção de maior igualdade econômica pelos $99 \%$ da população discriminados pela oligarquia financista global (Juris, 2012); Economia Solidária - movimento socioeconômico de produção e consumo focado na valorização e na igualdade do ser humano, ao invés da produção, que têm, entre seus propósitos, extinguir a pobreza (Gaiger, 2015); desenvolvimentismos progressistas - modelos de desenvolvimento socioeconômico adotados por países dos BRICS que desafiam, ao mesmo tempo que reforçam, modelos e teorias neoliberais discriminatórias liderados pelos EUA, que promovem injustiça e desigualdade em escala global (Bräutigam, 2011; Lipton, 2017).

Ao re-historicizarmos consumerismo nos EUA, mostramos que esse movimento não existiria sem a contribuição de contramovimentos não discriminatórios mobilizados por mundos emergentes interconectados. Assim como não existe modernidade sem colonialidade, mostramos que não existe consumerismo ou novo consumerismo oligárquico-populista sem contramovimentos não discriminatórios não racialistas que continuam sendo negados por historicismos informados pelo antiantiamericanismo civilizacional. Por conseguinte, argumentamos que não existe campo oligárquicopopulista de $O \& G$ e marketing sem a face não racialista e não discriminatória correspondente, que continua sendo mobilizada por uma maioria em escala global e negada pelo conhecimento dominante. Essa proposta de virada histórica decolonial - com e para uma maioria não discriminatória, representada aqui como um "ator político coletivo" heterogêneo e contingente (Dussel, 2008, p. 75) - junta-se, então, às práticas-teorias mobilizadas historicamente por populações de mundos emergentes engajadas em ir além dos historicismos discriminatórios que "deixam de fora tudo o que não interessa", para permitir a co-construção de presentes e futuros transmodernos que possam ser classificados como efetivamente "globais" (Müller, 2017, p. 325, tradução nossa) e não negados pelo anti-antiamericanismo civilizacional. 
Com as seguidas crises do capitalismo neoliberal global em transição para o autoritarismo populista mobilizado pela supremacia branca (Peters, 2018), incluindo irresponsabilidades populistas mobilizadas por oligarquias brancas e racializadas nos países dos BRICS (Lipton, 2017; Patrick, 2010), crescem as responsabilidades de mundos emergentes interconectados para a proposição de potenciais soluções de impacto global. Ilustrado pela construção e ascensão do NCG oligárquico-populista discriminatório com foco em países dos BRICS, crescem as responsabilidades de países emergentes na re-historicização do campo de $\mathrm{O} \& \mathrm{G}$, para que equívocos do passado não se repitam ou sejam magnificados.

Nossa perspectiva de globalização para $O \& G$ e marketing se inspira no historicismo transmoderno desenvolvido neste artigo e vai além das dicotomizações Ocidente versus resto do mundo, Sul versus Norte, América Latina versus América do Norte, ou acadêmicos versus não acadêmicos. Assim como alternativas de consumerismo não discriminatório tanto desestabilizam quanto reforçam o consumerismo oligárquico-populista discriminatório, é importante reconhecermos que historicismos transmodernos mobilizados por países emergentes continuarão sendo classificados como exemplos de não liberalismo irresponsável e alimentando dinâmicas civilizacionais anti-BRICS e antiantiamericanismo. É necessário constituir e reforçar comunidades heterogêneas, multifacetadas e instáveis (Dussel, 2008), vinculadas a mundos emergentes interconectados e focadas nos EUA. Mais especificamente, sugerimos então que outros casos de historicismo amnético nos EUA sejam investigados no Brasil por meio (e a partir) da perspectiva transmoderna desenvolvida neste artigo com e para maiorias racializadas - e em colaboração com pesquisadores, instituições e mundos emergentes dos EUA que priorizam demandas populares por justiça racial, com o propósito de recuperar passados, conhecimentos e alternativas discriminados naquele país por discursos corporações-sociedade oligárquico-populistas. Esses projetos transmodernos, nos âmbitos de pesquisa e educação em O\&G e marketing, podem promover uma alternativa para a internacionalização do conhecimento produzido no Brasil e para a construção de um campo não discriminatório e não racista responsável que seja efetivamente global e capaz de promover impactos sociais não apenas no Brasil, como demandado por diversos autores no país (Bertero, Alcadipani, Cabral, Faria, \& Rossoni, 2013; Lazzarini, 2017), mas também nos e a partir dos EUA e, consequentemente, nos e a partir dos diversos mundos que constituem o mundo global (Abdalla \& Faria, 2017; Mignolo, 2011).

\section{Referências}

Abdalla, M., \& Faria, A. (2017). Em defesa da opção decolonial em administração/gestão. Cadernos Ebape, 15(4). Recuperado de http://www.scielo.br/pdf/cebape/v15n4/1679-3951-cebape-15-04914.pdf. http://dx.doi.org/10.1590/1679-395155249

Acevedo, C. (2012). Larry Holmes vs. Gerry Cooney revisited. Retrieved from https://thelivingdaylights.co/2012/10/17/imagine-a-day-at-the-end-of-your-life-larry-holmesgerry-cooney-revisited-2/

Ajami, F. (2003). The falseness of anti-Americanism. Foreign Policy, (138), 52-61. http://dx.doi.org/10.2307/3183656

Allen, R. (2001). The globalization of white supremacy: Toward a critical discourse on the racialization of the world. Educational Theory, 5(4), 467-485. http://dx.doi.org/10.1111/j.17415446.2001.00467.x

Althouse, S. (2007, June 30). Holmes, Cooney's epic '82 clash tinged with racism [Web log post]. Retrieved November 16, 2017, from http://blog.pennlive.com/lehighvalley/2007/06/holmes_cooneys_epic_82_clash_t.html

Amaker, N. (1988). Civil rights and Reagan administration. Washington: Urban Institute. 
Andreasen, A. (1975). The disadvantaged consumer. New York: The Free Press.

Barley, S. (2010). Building an institutional field to corral a government: A case to set an agenda for $\begin{array}{llll}\text { organization } & \text { Studies. } & \text { Organization } & \text { Studies, }\end{array}$ http://dx.doi.org/10.1177/0170840610372572

Bartels, R. (1976). The history of marketing thought (2nd ed.). Columbus: Grid.

Baskin, J. (1988). The development of corporate financial markets in Britain and the United States, 1600-1914: Overcoming asymmetric information. Business History Review, 62(2), 199-237. http://dx.doi.org/10.2307/3115999

Beard, C. (1924). Contemporary American history - 1877-1913. New York: Macmillan.

Beck, U. (2002). The cosmopolitan society and its enemies. Theory, Culture \& Society, 19(1/2), 17-44. http://dx.doi.org/10.1177/026327640201900101

Bello, W. (1994). Dark victory: The United States, structural adjustment, and global poverty (2nd ed.). London: Pluto.

Bendix, R. (1956). Work and authority in industry: Managerial ideologies in the course of industrialization. New York: John Wiley \& Sons.

Berger, M. (2004). After the third world? History, destiny and the fate of the Third Worldism, Third World Quarterly, 25(1), 9-39. http://dx.doi.org/10.1080/0143659042000185318

Bertero, C., Alcadipani, R., Cabral, S., Faria, A., \& Rossoni, L. (2013). Os desafios da produção do conhecimento em administração no Brasil. Cadernos EBAPE.BR, 11(1), 181-196.

Bloom, P. (2016). Authoritarian capitalism in the age of globalization. Massachusetts: Edward Elgar.

Bräutigam, D. (2011). Aid 'with Chinese characteristics': Chinese foreign aid and development finance meet the OECD-DAC aid regime. Journal of International Development, 23(5), 752-764. http://dx.doi.org/10.1002/jid.1798

Brown, S. (1995). Life begins at 40? Further thoughts on marketing's "mid-life crisis". Marketing Intelligence \& Planning, 13(1), 4-17. http://dx.doi.org/10.1108/02634509510079333

Brownlie, D., \& Saren, M. (1995). On the commodification of marketing knowledge: Opening themes. $\begin{array}{llll}\text { Journal of Marketing } & \text { 11(7), }\end{array}$ http://dx.doi.org/10.1080/0267257X.1995.9964373

Brunstetter, D., \& Zartner, D. (2011). Just war against barbarians: revisiting the Valladolid debates between Sepúlveda and Las Casas. Political Studies, 59(3), 733-752. http://dx.doi.org/10.1111/j.1467-9248.2010.00857.x

Buskirk, R., \& Rothe, J. (1970). Consumerism: An interpretation. Journal of Marketing, 34(4), 61-65.

Ceaser, J. W. (2003). A genealogy of anti-Americanism. Public Interest, (17), 3-18.

Chalmers, D. (2003). Backfire: How the Ku Klux Klan helped the civil rights movement. Lanham: Rowman \& Littlefield.

Clark, P., \& Rowlinson, M. (2004). The treatment of history in organisation studies: Towards an 'historic turn'? Business History, 46(3), 331-352. http://dx.doi.org/10.1080/0007679042000219175

Cohen, L. (2003). A Consumers' republic: The politics of mass consumption in postwar America. New York: Alfred A Knopf. 
Conrad, S. (2010). Globalization and the Nation in Imperial Germany. Cambridge: Cambridge University.

Creighton, L. (1976). Pretenders to the throne. Lexington: Lexington Books.

Crockatt, R. (2003). America embattled: September 11, anti-americanism, and the global order. London: Psychology Press.

Day, G., \& Aaker, D. (1970). A guide to consumerism. Journal of Marketing, 34(3), 12-19. http://dx.doi.org/10.2307/1249814

De Genova, N. (2010). Antiterrorism, race, and the new frontier: American exceptionalism, imperial multiculturalism, and the global security state. Identities: Global Studies in Culture and Power, 17(6), 613-640. http://dx.doi.org/10.1080/1070289X.2010.533523

Dholakia, N., Firat, A. F., \& Bagozzi, R. P. (1980). The de-Americanization of marketing thought: In search of a universal basis. In C. Lamb \& P. Dunne (Eds.), Theoretical developments in marketing (pp. 25-29). Chicago: Marketing Classics Press.

Dijk, T. A. van (1993). Elite discourse and racism. London: Sage.

Donohue, K. (2010). Choosing conservatism in the 1930s: The political odyssey of F. J. Schlink. Journal of the Historical Society, 10(4), 437-473. http://dx.doi.org/10.1111/j.1540-5923.2010.00313.x

Dudziak, M. (2000). Cold war civil rights: Race and the image of American democracy. Princeton: Princeton University.

Dussel, E. (1994). 1942 - El encubrimiento del outro: Hacia el origen del "mito de la Modernidad". La Paz: Plural.

Dussel, E. (2008). Twenty theses on politics. Duke: Duke University.

Edwards, S., \& Harris, D. (2016). Black lives matter. North Mankato: Abdo Publishing.

Fanon, F. (1963). The wretched of the Earth. New York: Grove Press.

Faria, A., \& Hemais, M. (2017). Rethinking the bottom of the pyramid - A critical perspective from an emerging economy. Marketing Theory, 17(3), 271-287. http://dx.doi.org/10.1177/1470593117704283

Firat, A. (2010). Commentaries on the state of journals in marketing. Marketing Theory, 10(4), 437-455. http://dx.doi.org/10.1177/1470593110382827

Fotaki, M., \& Prasad, A. (2015). Questioning neoliberal capitalism and economic inequality in business schools. Academy of Management Learning \& Education, 14(4), 556-575. http://dx.doi.org/10.5465/amle.2014.0182

Friedman, M. P. (2012). Rethinking Anti-Americanism: The history of an exceptional concept in American Foreign relations. Cambridge: Cambridge University Press.

Gabriel, Y., \& Lang, T. (2006). The unmanageable consumer (2nd ed.). London: Sage.

Gaiger, L. I. (2015). A economia solidária na contramarcha da pobreza. Sociologia, Problemas e Práticas, (79), 43-63. http://dx.doi.org/10.7458/SPP2015793556

Ger, G., \& Belk, R. (1996). I'd like to buy the world a coke: Consumptionscapes of the "less affluent world". Journal of Consumer Policy, 19(3), 271-304. http://dx.doi.org/10.1007/BF00411411 
Gienow-Hecht, J. C. (2006). Always blame the Americans: Anti-Americanism in Europe in the twentieth century. The American Historical Review, 111(4), 1067-1091. http://dx.doi.org/10.1086/ahr.111.4.1067

Glickman, L. (2009). Buying power: A history of consumer activity in America. Chicago: University of Chicago.

Goldfrank, W. (1975). World system, state structure, and the onset of the Mexican revolution. Politics and Society, 5(4), 417-429. http://dx.doi.org/10.1177/003232927500500402

Hage, G. (2012). White nation: Fantasies of white supremacy in a multicultural society. New York and London: Routledge.

Hall, J. (2005). The long civil rights movement and the political uses of the past. Journal of the American History, 91(4), 1233-1263. http://dx.doi.org/10.2307/3660172

Hartman, A. (2015). A war for the soul of America: A history of the culture wars. Chicago: University of Chicago Press.

Harvey, D. (2007). Neoliberalism as creative destruction. The annals of the American Academy of Political and Social Science, 610(1), 21-44. http://dx.doi.org/10.1177/0002716206296780

Herrmann, R. (1982). The consumer movement in historical perspective. In D. Aaker \& G. Day (Eds.), Consumerism: Search for the consumer interest (4th ed., pp. 23-32). New York: Free Press.

Hilton, M. (2009). Prosperity for all: Consumer activism in an era of globalization. Ithaca: Cornell University.

Hodgson, G. (2004). Anti-Americanism and American exceptionalism. Journal of Transatlantic Studies, 2(1), 27-38. http://dx.doi.org/10.1080/14794010408656805

Hollander, P. (1995). Anti-Americanism: Irrational and rational. New Brunswick: Transaction.

Huntington, S. (1993). Why international primacy matters. International Security, 17(4), 68-83. http://dx.doi.org/10.2307/2539022

Hurrell, A. (2006). Hegemony, liberalism and global order: What space for would-be great powers? International Affairs, 82(1), 1-19. http://dx.doi.org/10.1111/j.1468-2346.2006.00512.x

Ibarra-Colado, E. (2006). Organization studies and epistemic coloniality in Latin America: Thinking otherness from the margins. Organization, 13(4), 489-508. http://dx.doi.org/10.1177/1350508406065851

James, H. (2011). International order after the financial crisis. International Affairs, 87(3), 525-537. http://dx.doi.org/10.1111/j.1468-2346.2011.00988.x

Joseph, P. (2006) (Ed.). The black power movement: Rethinking the civil rights - black power era. New York: Routledge.

Juris, J. (2012). Reflections on \#occupy everywhere: Social media, public space, and emerging logic of aggregation. American Ethnologist, 39(2), 259-279. http://dx.doi.org/10.1111/j.15481425.2012.01362.x

Katzenstein, P., \& Keohane, R. (2007). Varieties of anti-Americanism: A framework for analysis. In P. Katzenstein \& R. Keohane (Eds.), Anti-americanisms in world politics (pp. 9-38). Ithaca: Cornell University.

Kharas, H. (2010). The emerging middle class in developing countries [Working Paper n. 285]. OECD Development Centre, Paris, França. 
Kieser, A. (2004). The Americanization of academic management education in Germany. Journal of Management Inquiry, 13(2), 90-97. http://dx.doi.org/10.1177/1056492604265301

Kivenzor, G., \& Spohn, K. (2016). Luxury consumption in brics: Rationale behind 'irrational' consumption patterns. In K. Plangger (Ed.), Thriving in a new world economy (pp. 101-105). Cham: Springer.

Kolko, G. (1963). The triumph of conservatism - A reinterpretation of American History, 1900-1916. New York: Free Press.

Kotler, P. (1972). What consumerism means for marketers. Harvard Business Review, 50(3), 48-57.

Kotler, P., \& Zaltman, G. (1971). Social marketing: An approach to planned social change. Journal of Marketing, 35(3), 3-12. http://dx.doi.org/10.2307/1249783

Krastev, I., \& Mcpherson, A. (Eds.) (2007). The anti-American century. Budapest: Central European Union.

Lazzarini, S. (2017). Pesquisa em administração: Em busca de impacto social e outros impactos. Revista de Administração de Empresas, 57(6), 620-625. http://dx.doi.org/10.1590/s0034-759020170608

Lieber, R. J. (2008). Falling upwards: Declinism: The box set. World Affairs, 171(1), 48-56.

Lipton, M. (2017). Are the BRICS reformers, revolutionaries, or counter-revolutionaries? South African Journal of International Affairs, 24(1), 41-59. http://dx.doi.org/10.1080/10220461.2017.1321039

Livingstone, G. (2009). America's backyard - The United States \& Latina America - from the Monroe doctrine to the war on terror. London: Zed Books.

Lohin, R. (2017). Afterword: The history (and future history) of socially responsible business. In W. Pettigrew \& D. Smith (Eds.), A history of socially responsible business, cf. 1600-1950 (pp. 297304). Cham: Palgrave.

Markin, R. (1971). Consumerism: Militant consumer behavior - A social and behavioral analysis. Business and Society, 12(1), 5-17. http://dx.doi.org/10.1177/000765037101200101

Mayer, R. (1989). The consumer movement. Boston: Twayne.

McPherson, A. (2009). Yankee no! Anti-americanism in US - Latin America relations. Cambridge, MA: Harvard University.

Melamed, J. (2011). Represent and destroy - Rationalizing violence in the new racial capitalism. Minneapolis, MN: University of Minnesota Press.

Micheletti, M., Follesdal, A., \& Stolle, D. (Eds.) (2006). Politics, products and markets - Exploring political consumerism past and present. London: Transaction Publishers.

Micheletti, M., \& Stolle, D. (2012). Sustainable citizenship and the new politics of consumption. The ANNALS of the American Academy of Political and Social Science, 644(1), 88-120. http://dx.doi.org/10.1177/0002716212454836

Mignolo, W. (2011). The darker side of Western modernity: Global futures, decolonial options. Durham \& London: Duke University.

Müller, G. (2017). World history and perspectivity: Between necessity and opportunity. In R. C. Weller (Ed.), 21st-Century narratives of world history: Global and multidisciplinary perspectives (pp. 321-327). Cham: Palgrave Macmillan. 
Murphy, J., \& Willmott, H. (2015). The rise of the 1\%: an organizational explanation. In G. Morgan, P. Hirsch, \& S. Quack (Eds.). Elites on trial (pp. 25-53). Bingley: Emerald Group.

Nadel, M. (1971). The politics of consumer protection. Indianapolis: Bobbs-Merrill.

Nagel, T. (2005). The problem of global justice. Philosophy \& Public Affairs, 33(2), 113-147.

Noble, D. F. (1979) America by design: Science, technology, and the rise of corporate capitalism. Oxford: Oxford University.

Noble, D. W. (2002). Death of a nation: American culture and the end of exceptionalism. Minnesota: University of Minnesota Press.

Nye, J. (2004). Soft power and American foreign policy. Political Science Quarterly, 119(2), 255-270. http://dx.doi.org/10.2307/20202345

Oates, J. (1987). On boxing. Gordon City, NY: Dolphin/Doubleday.

Ogbar, J. (2005). Black power: Radical politics and African American identity. Baltimore: Johns Hopkins University Press.

Orser, C. (1998). The challenge of race to American history archeology. American Anthropologist, 100(3), 661-668. http://dx.doi.org/10.1525/aa.1998.100.3.661

Patel, R., \& Mcmichael, P. (2004). Third worldism and the lineages of global fascism: The regrouping of the global South in the neoliberal era. Third World Quarterly, 25(1), 231-254. http://dx.doi.org/10.1080/0143659042000185426

Patrick, S. (2010). Irresponsible stakeholders? The difficulty of integrating rising powers. Foreign Affairs, 89(6), 44-53. http://dx.doi.org/10.2307/20788715

Patterson, A., Bradshaw, A., \& Brown, S. (2008). 'Don't forget the fruit gums, chum': Marketing under erasure and renewal. Marketing Theory, 8(4), 449-463. http://dx.doi.org/10.1177/1470593108096545

Peters, M. (2018). The end of neoliberal globalization and the rise of authoritarian populism. $\begin{array}{llll}\text { Educational Philosophy } & \text { 323-325. }\end{array}$ http://dx.doi.org/10.1080/00131857.2017.1305720

Perrow, C. (2002). Organizing America: Wealth, power, and the origins of corporate capitalism. Princeton: Princeton University.

Pfeffer, J. (2008). What ever happened to pragmatism? Journal of Management Inquiry, 17(1), 57-60. http://dx.doi.org/10.1177/1056492607312770

Pieterse, J. (2011). Global rebalancing: Crisis and the East-South turn. Development and Change, 42(1), 22-48. http://dx.doi.org/10.1111/j.1467-7660.2010.01686.x

Piketty, T. (2014). Capital in the twenty first century. Cambridge: Harvard University.

Pollitt, D. (1960). Dime store demonstrations: Events and legal problems of first sixty days. Duke Law Journal, 9(3), 315-365. http://dx.doi.org/10.2307/1371082

Porter, M., \& Kramer, M. (2011). Creating shared value. Harvard Business Review, 89(1/2), 62-77.

Rahman, M. (1994). Consumer protection in Bangladesh: Law and practice. Journal of Consumer Policy, 17(3), 349-362. http://dx.doi.org/10.1007/BF01018968 
Ratner, C. (1968). Educating the low-income consumer: some viewpoints from an action program. Journal of Consumer Affairs, 2(1), 107-114.

Rocha, A. (2000). Empresas e clientes: Um ensaio sobre valores e relacionamentos no Brasil. São Paulo: Atlas.

Rollins, J. (1986). Part of a whole: The interdependence of the civil rights movement and other social movements. Phylon (1960-), 47(1), 61-70. http://dx.doi.org/10.2307/274695

Rotfeld, H. (2010). A pessimist's simplistic historical perspective on the fourth wave of consumer protection. Journal of Consumer Affairs, 44(1), 423-429. http://dx.doi.org/10.1111/j.17456606.2010.01176.x

Sales, W., Jr. (1994). From civil rights to black liberation: Malcolm X and the organization of AfroAmerican Unity. Boston: South End.

Santos, B. (2006). The rise of the global left: The world social forum and beyond. London: Zed Books.

Sauerbronn, F., \& Faria, A. (2009). A utilização do método histórico em pesquisa acadêmica de marketing. Estratégia e Negócios, 2(2), 78-95. http://dx.doi.org/10.19177/reen.v2e2200977-95

Schueller, M. (2007). Area studies and multicultural imperialism: The project of decolonizing knowledge. Social Text, 25(1), 41-62. http://dx.doi.org/10.1215/01642472-2006-016

Seymour, R. (2012). American insurgents: A brief history of American anti-imperialism. Chicago: Haymarket Books.

Shulman, M. (2000). The progressive era origins of the national security act. Dickinson Law Review, 104(2), 289-330.

Sklair, L. (2011). The culture-ideology of consumerism. In D. Southerton (Ed.), Encyclopedia of consumer cultures (pp. 407-409). London: Sage.

Slate, N. (2012) (Ed.). Black power beyond borders - The global dimensions of the black power movement. New York: Palgrave Macmillan.

Sombart, W. (1976). Why is there no Socialism in the United States? London: Palgrave.

Stephan, A. (Ed.) (2005). The Americanization of Europe: Culture, diplomacy, and anti-Americanism after 1945. New York and Oxford: Berghahn Books.

Storss, L. (2000). Civilizing capitalism: The national consumer's league, women's activism, and labor standards in the New Deal era. Chapel Hill: University of North Carolina.

Sturdivant, F., \& Wilhelm, W. (1969). Poverty, minorities, and consumer exploitation. In F. Sturdivant (Ed.), The ghetto marketplace (pp.108-117). New York: Free Press.

Swagler, R. (1994). Evolution and applications of the term consumerism: theme and variations. Journal of Consumer Affairs, 28(2), 347-360. http://dx.doi.org/10.1111/j.1745-6606.1994.tb00856.x

Tadajewski, M. (2006). The ordering of marketing theory: The influence of McCarthyism and the cold war. Marketing Theory, 6(2), 163-199. http://dx.doi.org/10.1177/1470593106063982

Tadajewski, M. (2008). Final thoughts on amnesia and marketing theory. Marketing Theory, 8(4), 465484. http://dx.doi.org/10.1177/1470593108096546

Tadajewski, M., \& Sarens, M. (2008). The past is a foreign country: Amnesia and marketing theory. Marketing Theory, 8(4), 323-338. http://dx.doi.org/10.1177/1470593108096539 
Tamames, M. (2005). La cultura del mal. Madrid: Ediciones Espejo de Tinta.

Tiemstra, J. (1992). Theories of regulation and the history of consumerism. International Journal of Social Economics, 19(6), 3-27. http://dx.doi.org/10.1108/03068299210012548

Toyer, A. (1968). Consumer education and low-income families. Journal of Consumer Affairs, 2(1), 114-120. http://dx.doi.org/10.1111/j.1745-6606.1968.tb00776.x

Turner, F. J. (1921). The frontier in American history. New York: Henry Holt.

Varman, R., \& Belk, R. (2009). Nationalism and ideology in an anticonsumption movement. Journal of Consumer Research, 36(4), 686-700. http://dx.doi.org/10.1086/600486

Varman, R., \& Sreekumar, H. (2015). Locating the past in its silence: History and marketing theory in India. Journal of Historical Research in Marketing, 7(2), 272-279. http://dx.doi.org/10.1108/JHRM-04-2013-0016

Varul, M. (2013). Towards a consumerist critique of capitalism: A socialist defence of consumer culture. Ephemera, 13(2), 293-315.

Vitalis, R. (2000). The graceful and generous liberal gesture: Making racism invisible in American $\begin{array}{llll}\text { international } & \text { relations. } & \text { Millennium, }\end{array}$ http://dx.doi.org/10.1177/03058298000290020701

Vogel, D. (2006). Tracing the American roots of the political consumerist movement. In M. Micheletti, A. Follesdal, \& D. Stolle (Eds.), Politics, products and markets - Exploring political consumerism past and present (pp. 83-100). London: Transaction.

Wall, W. L. (2009). Inventing the "American way": The politics of consensus from the new deal to the civil rights movement. Oxford: Oxford University Press.

Weatherbee, T., Mclaren, P., \& Mills, A. (2015). Introduction: The historic turn in management and organizational studies: A companion reading. In P. Mclaren, A. Mills, \& T. Weatherbee (Eds.), The routledge companion to management and organizational history (pp. 3-10). London: Routledge.

Westwood, R., \& Clegg, S. (2003). Debating organization: Point-counterpoint in organizations studies. Oxford: Blackwell Publishing.

Westwood, B., Jack, G., \& Frenkel, M. (2014). Situating core-peripheral knowledge in management and organisation studies. In B. Westwood, G. Jack, F. Khan, \& M. Frenkel (Eds.), Core-periphery relations and organisation studies (pp. 1-32). London: Palgrave Macmillan.

Winant, H. (1994). Racial conditions: Politics, theory, comparisons. Minneapolis: University of Minnesota.

Young, C. (2006). Soul power: Culture, radicalism, and the making of a U.S. third world left. Durham: Duke University Press Books. 


\section{Dados dos Autores}

Alexandre Faria

Edifício Luiz Simões Lopes, Praia de Botafogo, 190, Botafogo, 22250-900, Rio de Janeiro, RJ, Brasil. E-mail: alex.faria@fgv.br, alex.faria.br@gmail.com. https://orcid.org/0000-0001-9095-725X

Marcus Wilcox Hemais

Rua Marquês de São Vicente, 225, Gávea, 22271-042, Rio de Janeiro, RJ, Brasil. E-mail: mhemais@gmail.com.. https://orcid.org/0000-0001-9181-8446 